\title{
3D HABITAT COMPLEXITY OF CORAL REEFS IN THE NORTHWESTERN HAWAIIAN ISLANDS IS DRIVEN BY CORAL ASSEMBLAGE STRUCTURE
}

\author{
J. H. R. Burns ${ }^{1 *}$, A. Fukunaga 2,3, K. H. Pascoe ${ }^{1}$, A. Runyan¹, B. K. Craig ${ }^{1}$, J. Talbot ${ }^{1}$, A. Pugh ${ }^{1}$, R. K. Kosaki ${ }^{3}$ \\ ${ }^{1}$ Marine Science Department, University of Hawai`i at Hilo, 200 West Kawili St., Hilo, HI 96720, USA - (johnhr, kpascoe, \\ atrunyan, bkcraig, jtalbot, apugh6)@hawaii.edu \\ 2 Joint Institute for Marine and Atmospheric Research, University of Hawai`i at Mānoa, Honolulu, HI 96822, USA - \\ atsuko.fukunaga@noaa.gov \\ ${ }^{3}$ Papahānaumokuākea Marine National Monument, Office of National Marine Sanctuaries, National Ocean \\ Service, National Oceanic and Atmospheric Administration, Honolulu, HI 96818, USA - randall.kosaki@noaa.gov
}

Commission II - WGII/9

KEY WORDS: Coral Reefs, Coral Ecology, Photogrammetry, Structure-from-Motion, 3D Reconstruction, Habitat Complexity, Benthic Community Structure

\begin{abstract}
:
Corals act as ecosystem engineers by secreting structurally complex calcium carbonate skeletons on the benthic substrate that provide habitat for a diverse array of associated reef organisms. Communities of living corals create large and dynamic benthic structures that directly affect ecological parameters such as habitat provisioning and light availability, thus influencing overall ecosystem function. Despite the important role 3D structural complexity plays in ecosystem biodiversity and productivity, the field of coral ecology has lacked accessibility to practical technology capable of quantifying $3 \mathrm{D}$ characteristics of underwater habitats. Advancements in the field of computer vision has led to Structure-from-Motion (SfM) photogrammetry, which provides a simple and cost-effective method for creating high-resolution and spatially accurate 3D reconstructions of natural environments. Integrating SfM approaches into coral reef research and monitoring has provided useful insight into the relationship between $3 \mathrm{D}$ habitat complexity and ecological processes. In this study, we examined the relationships among 2D estimates of live coral cover and several metrics of 3D habitat structural complexity among eleven long-term monitoring sites at French Frigate Shoals. Our findings show that coral assemblage structure acts as a significant driver of 3D structural complexity of coral reef habitats at this atoll. This study highlights the importance of diverse and abundant coral assemblages in supporting structurally complex coral reef habitats and provides a framework for future investigations into the ecological role of various coral morphotypes.
\end{abstract}

\section{INTRODUCTION}

Coral reefs are some of the most productive and diverse ecosystems on the planet. Unfortunately, coral reefs are also threatened by an array of global and local stressors that have led to large-scale mortality and loss of live coral throughout the world's ocean (Harvell et al. 2007, Hoegh-Guldberg et al. 2007, Hughes et al. 2018). The frequency and severity of environmental stressors are predicted to increase (Knowlton 2001, Hughes et al. 2003, Hughes et al. 2018), thus it is critically important to quantify how subsequent shifts in coral assemblage structure will alter ecological processes and ecosystem services.

The $3 \mathrm{D}$ physical structure of habitats plays a fundamental role in the organization, function, and resilience of ecosystems (Nash et al. 2014, Richardson et al. 2017). Habitat structural complexity has been shown to support high levels of abundance and diversity of associated taxa across a range of environments (Huston 1979, Guinan et al. 2009, Graham and Nash 2013). Complex and dynamic habitat facilitates an array of ecological niche space at various spatial scales which provides refugia for a multitude of species (Crowder and Cooper 1982, Stachowicz 2001). The structural complexity of habitats is typically created by communities of ecosystem engineers (e.g., trees, seaweeds, oysters, grasses, corals), which are any organism that creates, modifies, maintains, or destroys a habitat (Jones et al. 1996, Richardson et al. 2017). 3D habitat structural complexity on coral reefs is primarily driven by the abundance of live sessile reefforming corals. Corals are structurally diverse organisms that exhibit a range of morphologies (e.g., massive, branching tabulate, encrusting, or foliose) and high levels of environmental plasticity (Todd 2008). The architecturally complex habitats created by living corals support some of the most diverse, productive, and economically valuable ecosystems on the planet
(Costanza et al. 1997, Moberg and Folke 1999, Hoegh-Guldberg et al. 2007).

Over the past decades, research conducted on reefs throughout the global ocean has found the loss of live coral to be associated with reductions in habitat complexity, which in turn has caused a decline in the abundance and diversity of associated reef fish and invertebrates (Graham et al. 2006, Alvarez-Filip et al. 2009, Walker et al. 2009, Graham and Nash 2013). Corals exhibit differential susceptibilities to disturbances, thus persistent disturbance events can result in homogenized coral assemblages dominated by stress tolerant species (Pratchett et al. 2011, Darling et al. 2013, Richardson et al. 2017). Morphologically complex corals that exhibit intricate branching, plating, and corymbose morphologies are generally more susceptible to disturbance and disease (Gates and Ainsworth 2011, Woesik et al. 2011). Disturbance events can lead to reductions in the abundance of these structurally complex corals and result in significant declines in 3D structural complexity of coral reef habitats (Burns et al. 2016, Couch et al. 2017, Magel et al. 2019). Our changing climate is likely to result in shifts of coral assemblage structure which will impact the habitat structural complexity of coral reefs. Currently, the link between coral assemblage structure and 3D habitat complexity is poorly understood. More research is needed to identify the connections between coral assemblage structure and 3D reef structural complexity in order to predict how coral reef ecosystem function will be altered under future climate conditions.

A primary challenge in linking coral assemblage structure to 3D habitat structural complexity has been the lack of available techniques for quantifying $3 \mathrm{D}$ features underwater. The proportion of live coral cover on a reef has been the most commonly used metric for characterizing coral communities 
(Leujak and Ormand 2007, House et al. 2018). While there are a multitude of specific approaches for estimating live coral cover, the simplicity of this metric is conducive for rapid and standardized monitoring across a range of spatial scales (House et al. 2018). Unfortunately, the link between 3D reef complexity and live coral assemblage structure cannot be captured by solely implementing conventional 2D approaches into monitoring programs (Alvarez-Filip et al. 2011, Graham and Nash 2013). Accurate measurements of 3D habitat structural complexity are needed to determine how changes in coral assemblage structure can impact the physical structure of reef habitats and alter largescale ecological processes and ecosystem services.

Coral reef ecologists have long recognized that the 3D structural features of coral reefs influence important ecological processes (Risk 1972, Luckhurst and Luckhurst 1978, MacArthur 1984, Kostylev et al. 2005). However, due to high cost and difficulty of implementing 3D techniques into monitoring programs, the field of coral ecology has only recently developed practical approaches for quantifying 3D characteristics of coral reefs (Burns et al. 2015, Figueira et al. 2015, Leon et al. 2015, Ferrari et al. 2016, Burns et al. 2016). These new innovative approaches rely on Structure-from-Motion (SfM) photogrammetry, which is a cost-effective and automated range imaging technique for estimating three-dimensional structures from two-dimensional image sequences (Snavely et al. 2008, Westoby et al. 2012, Fonstad et al. 2013). SfM photogrammetry processes overlapping imagery with scale-invariant feature transform (SIFT), which is a feature detection algorithm in computer vision that detects and describes local features in images. This technique does not require known 3D locations prior to calculating camera positions, and thus provides a fast and simple method for generating high resolution 3D models of natural environments (Westoby et al. 2012). The 3D products (e.g., point clouds, digital elevation models, digital surface models, orthophotomosaics) derived from SfM photogrammetry have been demonstrated to have high precision and accuracy across multiple spatial scales that are comparable to other $3 \mathrm{D}$ remote sensing techniques such as LiDAR (Delparte et al. 2014, Javernick et al. 2014, Remondino et al. 2014, Storlazzi et al. 2016). The ability to create highresolution $3 \mathrm{D}$ reconstructions of coral reef habitats dramatically enhances the ability of research to study the connections between structural complexity and ecosystem function.

This study aimed to improve our understanding of how conventional 2D coral reef survey metrics (proportion of live coral cover) are associated with 3D reef structural complexity. We used coral reef survey data from the Northwestern Hawaiian Islands (NWHI). The NWHI consist of ten major islands and atolls that span approximately 2000-km (Figure 1a). They are part of the Papahānaumokuākea Marine National Monument, a marine protected area encompassing 1.5 million square kilometers that is one of the largest conservation areas in the world. The monitoring of shallow-water $(\leq 30 \mathrm{~m})$ coral reef fish and reef habitats is conducted annually in the NWHI as part of the reef assessment and monitoring program (RAMP). One primary objective of these expeditions is to characterize coral health and assemblage structure throughout the NWHI. Since 2012, we have conducted 3D surveys of long-term study sites in conjunction with annual RAMP surveys. For this study, we conducted multiple regression and multivariate analyses to determine how 2D estimates of live coral cover (delineated by coral genus and morphology) are related to values of 3D reef structural complexity at eleven long-term monitoring sites throughout French Frigate Shoals, the largest atoll in the NWHI (Figure 1b). The results from this study provide valuable insight into how $2 \mathrm{D}$ estimates of live coral cover are associated with $3 \mathrm{D}$ habitat complexity on coral reefs.
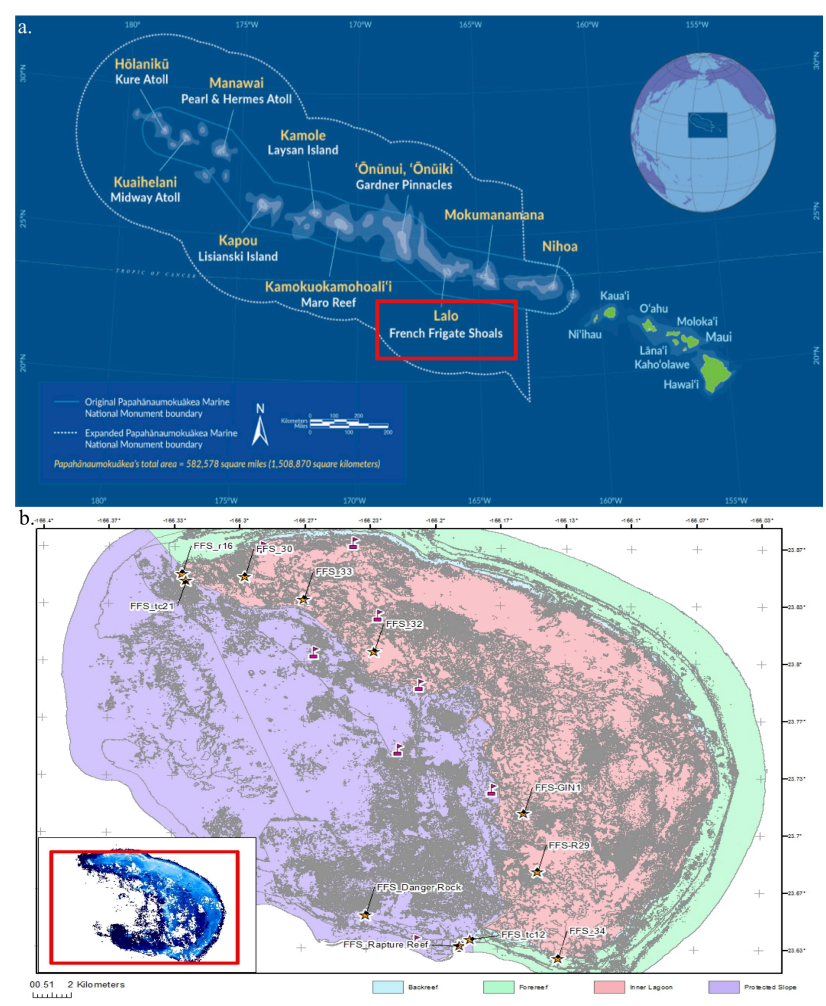

Figure 1. Site images showing a) the islands and atolls within the Papahānaumokuākea Marine National Monument and, b) the specific locations of long-term monitoring sites (indicated by star symbols) at French Frigate Shoals.

\section{METHODS}

\subsection{Image acquisition}

Images were collected from coral reef study plots at French Frigate Shoals $\left(23^{\circ} 43^{\prime} 03.2^{\prime \prime} \mathrm{N}, 166^{\circ} 11^{\prime} 10.2^{\prime \prime} \mathrm{W}\right)$, an atoll located in the Papahānaumokuākea Marine National Monument. All surveys were conducted during a 2017 research expedition aboard NOAA Ship Hi‘ialakai (R 334, National Oceanic and Atmospheric Administration). Divers using SCUBA surveyed two $5 \times 10-\mathrm{m}$ plots at eleven long-term monitoring sites distributed throughout the atoll (Figure 1b). Each plot is marked with permanently installed pins to demarcate the $5 \times 10-\mathrm{m}$ plot area. Ground control points (GCPs) and scale bars were placed at each end of the survey plot to enable accurate orthorectification of the resulting 3D models. The divers collected overlapping (70$80 \%$ ) planar images of the benthic substrate while swimming in a boustrophodonic pattern approximately 1-m above the substrate following the methods developed by Burns et al. 2015. All photos were taken with either a Canon 5D Mark III digital SLR camera with a 24-mm lens in an Ikelite housing with a $20-\mathrm{cm}$ hemispheric dome port or a Canon EOS Rebel SL1 digital SLR camera with an 18-55 $\mathrm{mm}$ lens in an Ikelite housing with a 15cm dome port.

\subsection{D reconstructions}

3D reconstructions were rendered using Agisoft PhotoScan software (Agisoft LLC., St. Petersburg, Russia). The image processing workflow was conducted in the following phases: 1) image alignment, 2) generation of sparse 3D point cloud, 3) GCP scaling and image optimization, 4) generation of dense 3D point cloud, 5) rendering of continuous mesh model, 6) rendering of textured digital surface model, and 7) rendering of a digital elevation model (DEM) and orthomosaic. The 3D 
reconstructions were orthorectified by creating a local coordinate system for each plot using the known spatial $\mathrm{x}-, \mathrm{y}-$, and $\mathrm{z}$ - values associated with the GCPs. The DEM is a raster file that represents the $3 \mathrm{D}$ elevation of the reef substrate as a grid of squares, and the orthomosaic is an orthorectified, high-resolution image created by stitching the source photos used for 3D reconstruction. The orthomosaics and DEM are projected using the same local coordinate system so they can be layered to perform identification and measurement of individual coral colonies (Burns et al. 2015).

\subsection{Estimation of live coral cover and quantification of 3D habitat structural complexity}

Orthomosaics were uploaded into CoralNet software to quantify estimates of live coral cover for each survey plot (Beijbom et al., 2012). 1000 random points were annotated onto each orthomosaic and each point was manually classified. All abiotic and biotic features were annotated, and live coral was classified down to genus level and associated morphology (e.g., tabulate Acropopra). The proportion of each annotation category was used to determine estimates of live coral cover for each long-term study plot.

Metrics of 3D habitat structural complexity were quantified using $3 D$ analyst and spatial analyst tools in ArcMap geospatial software (ArcGIS 10.5, Environmental Systems Resource Institute, Redlands, USA). The DEM and orthomosaics were uploaded into ArcMap and the editor tool was used to digitize the $5 \times 10-\mathrm{m}$ spatial area of the long-term study plots. The DEM and orthomosaic from each study plot were layered together in order to analyze 3D structural characteristics among all surveyed sites. The cell size of the DEM was set to $1.0-\mathrm{cm}$ to quantify fine-scale variability in the 3D structural complexity of each study plot. The following geospatial metrics were quantified from the DEMs to analyze 3D structural characteristics that are known to affect the biodiversity and abundance of marine organisms (Kostylev et al., 2005, Noonan et al. 2012, Figueira et al. 2015).

Surface complexity values were calculated as the ratio of the total 3D surface area to the total 2D surface area of the digitized survey plot area. Slope values were calculated using the Benthic Terrain Modeler tool, which computes slope on a geodesic plane using a $3 \times 3$ cell neighborhood and improves on the planar method by measuring the angle between the surface and the local x-, y-, zcoordinates for each of the 8 adjacent cells and is fitted with least squares (Walbridge et al. 2018). Curvature values were computed using the ArcMap spatial analyst tool. Curvature is the second derivative of the bathymetric surface, or the first derivative of slope. Curvature is evaluated by first calculating the second derivative for each cell in the surface using a moving $3 \times 3$ window, and then fitting a fourth order polynomial to the values within the window (Walbridge et al. 2018). Curvature is also quantified in a parallel direction to slope (profile curvature) and a perpendicular direction to slope (planiform curvature). Positive and negative curvature values represent upwardly concave or upwardly convex surfaces, respectively, and provide a method to describe the concave and convex nature of the benthic substrate such as peaks, ridges, channels, and planar regions.

Fractal dimension was calculated from the DEM of each survey plot with R statistical software (version 3.5.1) using the methods developed by Fukunaga et al. 2019. Each DEM was processed using the aggregate function to compute the fractal dimension of the benthic substrate across multiple resolutions; $1-\mathrm{cm}$ to $2,4,8$, 16,32 and $64-\mathrm{cm}$. Conducting this procedure results in one fractal dimension value $(D)$ for each study plot, which represents a ratio of the resolution of the raster DEM to the 3D surface area of the DEM across the multiple resolutions used for the analysis.
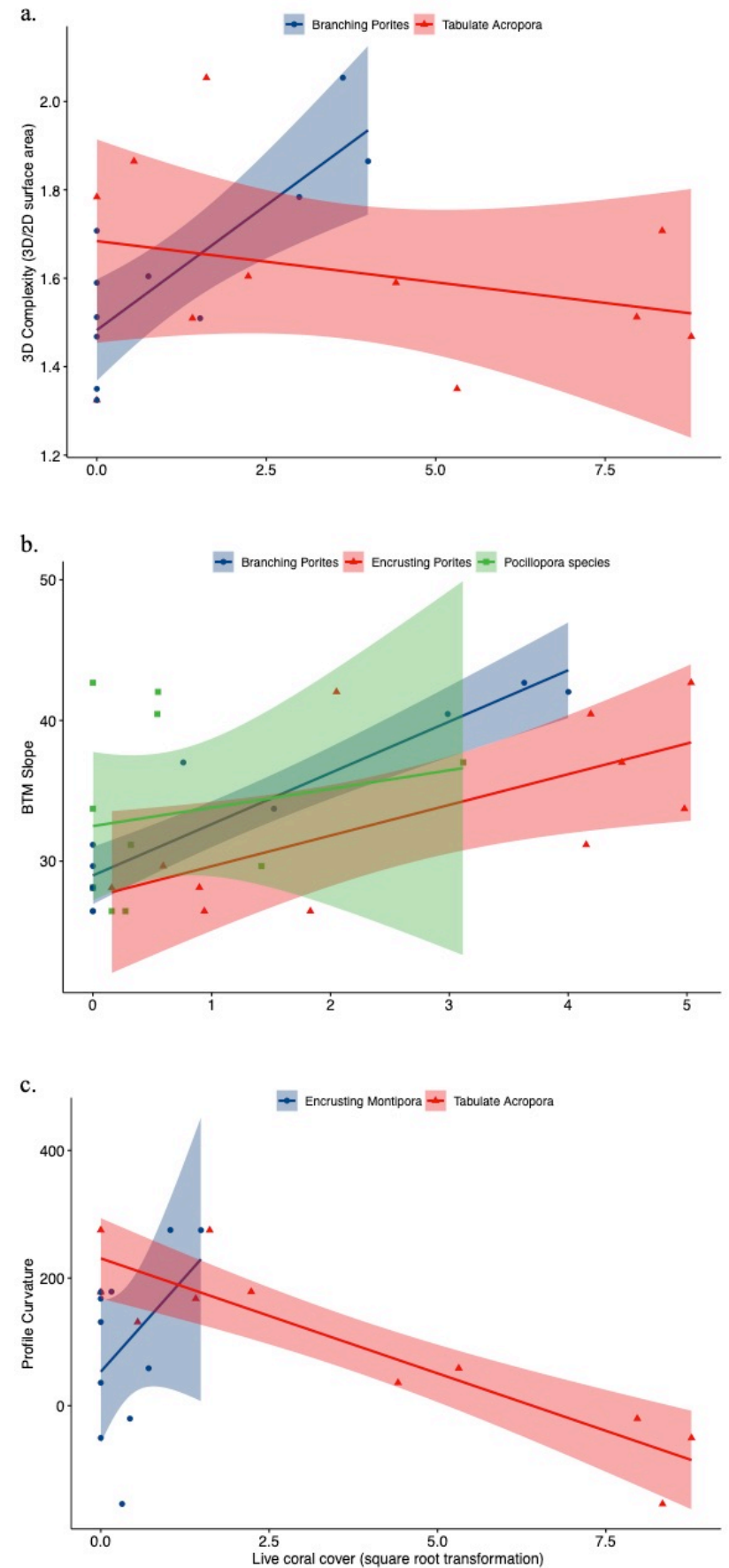

Figure 2. Plots representing the relationships among estimates of live coral cover and 3D habitat structural complexity identified by DISTLM. a) branching Porites $\left(\mathrm{R}^{2}=67.3 \%, \mathrm{p}<\right.$

$0.1)$ and tabulate Acropora $\left(\mathrm{R}^{2}=77.5 \%, \mathrm{p}<0.01\right)$ affect $3 \mathrm{D}$ complexity, b) Pocillopora corals $\left(\mathrm{R}^{2}=97.2 \%, \mathrm{p}<0.01\right)$ and both branching $\left(\mathrm{R}^{2}=87.1 \%, \mathrm{p}<0.01\right)$ and encrusting $\left(\mathrm{R}^{2}=91.9 \%\right.$, $\mathrm{p}<0.05)$ Porites affect BTM slope $(\mathrm{p}<0.01)$, c) encrusting Montipora $\left(\mathrm{R}^{2}=91.0 \%, \mathrm{p}<0.05\right)$ and tabulate Acropora $\left(\mathrm{R}^{2}=\right.$ $81.9 \%, \mathrm{p}<0.01)$ affect profile curvature.

\subsection{Statistical Analysis}

Estimates of live coral cover derived from the CoralNet annotations were used to statistically examine how 2D metrics of 
coral assemblage structure affect the 3D structural complexity of coral reef habitats at sites throughout French Frigate Shoals. Live coral taxa that contributed to less than $1 \%$ of the benthic habitat at all of the sites were removed from the analyses, except for massive Porites because all other Porites morphologies were included in the analyses. The estimates of live coral cover were square-root transformed and used to compute Bray-Curtis dissimilarity values to serve as a metric of coral assemblage structure. Canonical analysis of principal coordinates (CAP: Anderson and Robinson 2003, Anderson and Willis 2003) was used to explore relationships between $3 \mathrm{D}$ habitat structural complexity and the structure of coral assemblage on the basis of the Bray-Curtis dissimilarity. The multivariate CAP analysis identified principal coordinate axes that have maximum correlations with the metrics of 3D habitat structural complexity (surface complexity, slope, curvature). Fractal dimension was excluded from this analysis in order to avoid issues of multicolinearity as surface complexity and fractal dimension had very strong positive correlation of 0.95 . We also used univariate distance-based linear models (DISTLM: Legendre and Anderson, 1999, McArdle and Anderson, 2001) to examine formally how estimates of live coral cover affect the metrics of 3D habitat structural complexity (surface complexity, slope, curvature, and fractal dimension). The small-sample-size corrected version of Akaike's information criterion (AICc) was used to select appropriate parsimonious models and identify the coral genera and morphology that best explained variability in the levels of 3D habitat structural complexity among the study sites at French Frigate Shoals. All statistical analyses were done using the software package PRIMER 6 with the PERMANOVA+ addon (PRIMER-e, Auckland, New Zealand).

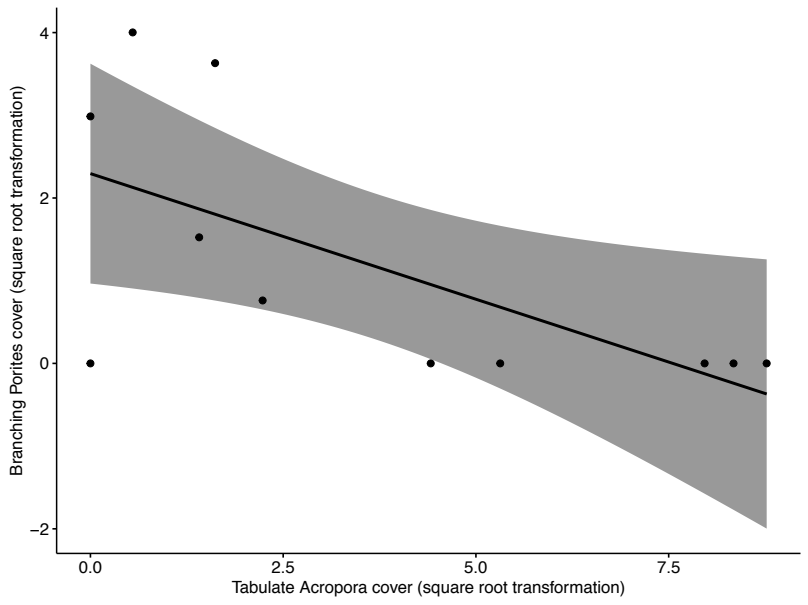

Figure 3. Plot representing the negative relationship between the percentage of live tabulate Acropora coral cover and the percentage of live branching Porites coral cover $\left(\mathrm{R}^{2}=41.9 \%, \mathrm{p}\right.$ $<0.05$ ) identified by DISTLM.

\section{RESULTS}

The CAP multivariate analysis indicated a strong association between the structure of coral assemblages (based on Bray-Curtis dissimilarity computed on square-root transformed live coral cover) and metrics of 3D habitat structural complexity (trace statistic $=1.2, p=0.002$ ). Two canonical axes produced in the analyses had canonical correlations of $\delta_{1}=0.94$ and $\delta_{2}=0.57$. The constrained CAP ordination (Figure 4) showed changes in the coral assemblage structure, from left to right, with an increase in profile curvature, while changes in the assemblage structure associated with increases in slope and 3D surface complexity, to a lesser extent, were captured from top to bottom. Levels of live coral cover at each survey site that were superimposed on the CAP ordination (Figure 4) showed a potential negative correlation between taburate Acropora and profile curvature and a positive correlation between overall coral cover and either slope or 3D surface complexity.

The univariate DISTLM analysis showed that the metrics of 3D habitat structural complexity are significantly affected by estimates of live coral cover (Figure 2). The percentage of branching Porites coral cover exhibited a statistically significant positive relationship with surface complexity explaining $67.3 \%$ of variation, and the percentage of tabulate Acropora coral cover exhibited a positive relationship, explaining additional $10 \%$ of variation in surface complexity after the percentage of branching Porites was taken into account (selected model's $\mathrm{R}^{2}=77.5 \%$, Figure 2a). It should be noted that the surface complexity and fractal dimension data exhibit Simpson's paradox; a phenomenon in probability and statistics in which a trend appears in several different groups of data but disappears or reverses when these groups are combined. Tabulate Acropora coral cover exhibits a negative trend with surface complexity and fractal dimension (Figure 2a), but when analysed using DISTLM and branching Porites coral cover is accounted for, the relationship between Acropora coral cover and surface complexity is positive. The percentage of branching Porites coral cover and tabulate Acropora coral cover explained $54.0 \%$ and additional $15.2 \%$, respectively, of variation in fractal dimension (selected model's $\mathrm{R}^{2}=69.2 \%$ ). Due to the strong collinearity between values of surface complexity and fractal dimension, only the plot of live coral cover and surface complexity is shown in Figure 2. The percentage of branching Porites coral cover, encrusting Porites coral cover, and Pocillopora coral cover exhibited statistically significant positive relationships with slope explaining $87 \%$, additional $4.7 \%$, and additional $5.4 \%$, respectively, of variation in slope (selected model's $\mathrm{R}^{2}=97.2$, Figure $2 b$ ). The percentage of tabulate Acropora coral cover exhibited a statistically significant negative relationship with profile curvature explaining $81.9 \%$ of variation, and the encrusting Montipora coral cover exhibited a statistically significant positive relationship, explaining additional $9.1 \%$ of variation in profile curvature (selected model's $\mathrm{R}^{2}=91.0$, Figure $2 \mathrm{c}$ ). The percentage of live tabulate Acropora coral cover was found to exhibit a significantly negative relationship with the percentage of live branching Porites coral cover $\left(\mathrm{R}^{2}=41.9 \%, \mathrm{p}<0.05\right.$, Figure 3 ).

\section{CONCLUSIONS}

This study examined how 2D estimates of live coral cover are associated with 3D structural complexity of coral reef habitats at French Frigate Shoals. Our analyses found coral assemblage structure and the percentage of live coral to be significant drivers of $3 \mathrm{D}$ habitat structural complexity among eleven long-term coral reef study sites. Our findings provide useful information for conservation efforts as they provide a framework for identifying specific coral morphotypes that act as drivers of $3 \mathrm{D}$ architectural complexity on coral reefs.

Our CAP analysis found statistically significant associations between the structure of coral assemblages at our long-term study sites and 3D habitat structural complexity (Figure 4). Metrics of 3D habitat structural complexity used in the analysis together exhibited a statistically significant correlation with the coral assemblages as a whole. The sites were separated from left to right along a gradient of profile curvature and top to bottom along gradients of structural complexity. The sites with a high percentage of live tabulate Acropora coral cover grouped at the bottom left thus tend to have high values of surface complexity and slope and low values of profile curvature, whereas sites dominated by a high percentage of live Porites coral cover and Montipora coral cover at the bottom right tend to have high 
values of surface complexity, slope, and profile curvature (Figure 4). This multivariate analysis is useful for exploring relationships between two sets of multivariate data, thus was utilized here to assess the relationships among both $2 \mathrm{D}$ and $3 \mathrm{D}$ reef characteristics and choose 3D habitat variables for formal analyses using DISTLM. Metrics of 3D habitat complexity are in some cases highly correlated (e.g., surface complexity and fractal dimension), thus it is important to examine the distributions of these variables prior to any analyses. The CAP analysis shows how patterns in coral assemblage structure are intricately linked to a set of $3 \mathrm{D}$ habitat variables and play an important role in determining the 3D structural complexity of coral reefs. This finding illustrates the importance of recognizing that both levels of live coral and diversity in coral morphotypes play critical roles in maintaining habitat complexity on coral reefs.

Our DISTLM analysis found several coral genera and morphologies exhibit statistically significant relationships with metrics of 3D habitat structural complexity. 3D complexity, measured as $3 \mathrm{D}$ surface area divided by $2 \mathrm{D}$ surface area, and fractal dimension exhibit a strong positive relationship with live cover of branching Porites corals (Figure 2a). This finding supports previous studies which have found branching coral morphologies to act as positive drivers of structural complexity on coral reefs (Alvarez-Filip et al., 2011, Burns et al. 2015, Leon et al. 2015, Magel et al. 2019). Interestingly, live cover of tabulate Acropora corals exhibits a negative trend with $3 \mathrm{D}$ complexity (Figure 2a) and fractal dimension. As discussed in the results, these data exhibit Simpson's paradox. When the data are analysed using DISTLM and branching Porites coral cover is accounted for, the relationship between Acropora coral cover and both surface complexity and fractal dimension is positive. Previous 3D reef characterization conducted at this atoll found tabulate and branching coral species to possess values of $3 \mathrm{D}$ complexity that are statistically significantly greater than other coral species and abiotic benthic features (Burns et al. 2015). The trends in the data and DISTLM results (Figure 2a) highlight how branching and tabulate coral morphologies are stronger drivers of $3 \mathrm{D}$ complexity and coral assemblage structure plays an important role in determining overall levels of 3D habitat structural complexity. The inverse relationship between values of tabulate Acropora coral cover and branching Porites coral cover (Figure 3 ) shows that shifts in the dominant coral morphotype of a coral assemblage can have significant impacts on $3 \mathrm{D}$ reef structure.

Values of slope, measured using the Benthic Terrain Modeler tool (Walbridge et al. 2018), exhibited statistically significant positive relationships with the percentage of branching Porites, encrusting Porites, and Pocillopora coral cover (Figure 2b). This finding supports other studies that have shown high values of coral cover promote more structurally complex coral reef habitat (Couch et al. 2017, Magel et al. 2019). The variability in the slope of each linear model (Figure $2 b$ ) provides more evidence of the importance of coral assemblage structure in driving $3 \mathrm{D}$ characteristics of reef habitats. Similar to 3D complexity, values of slope are most strongly affected by the percentage of branching Porites coral cover. These findings stress the important role that branching coral morphotypes play in shaping the physical 3D structure or coral reefs at French Frigate Shoals.

We found profile curvature to exhibit a statistically significant positive relationship with the percentage of live encrusting Monitpora coral and a negative relationship with the percentage of live tabulate Acropora coral (Figure 2c). Positive values of profile curvature represent concave surface and negative values represent convex surface (Burns et al. 2015, Walbridge et al. 2018). These findings show how each morphotype provides unique 3D physical characteristics to overall reef habitat complexity. At our long-term monitoring sites, encrusting coral are providing concave structure and tabulate corals provide convex structure. Analyzing 3D reef structure in the context of coral assemblage structure provides a unique perspective for understanding drivers of habitat complexity. The results presented here suggest high levels of coral cover of these morphotypes (encrusting and tabulate) provide a juxtaposition of concave and convex surface, which may provide more dynamic habitat space for associated reef organisms. This supports the notion that coral assemblage structure, rather than a single estimate of live coral cover, is a better predictor of 3D reef architecture as different combinations of coral morphotypes will produce unique 3D structure.

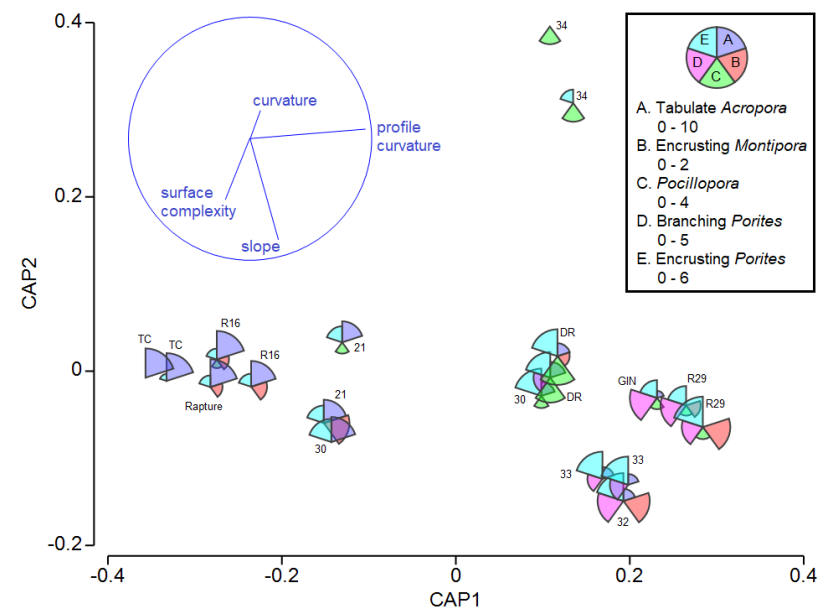

Figure 4. CAP constrained ordination using the Bray-Curtis dissimilarity values computed from live coral cover at the study sites. Vector overlays show gradients of 3D habitat metrics used in the analysis. Live coral cover (see legend) at each study site is superimposed on the ordination for references.

The field of coral ecology needs more studies focused on understanding the dynamics of habitat complexity as it is known to be an important driver of ecosystem diversity and productivity (Goreau 1959, Knudby and LeDrew 2007, Walker et al. 2009, Dustan et al. 2013). Despite the acknowledged importance of structural complexity, the field of coral reef ecology has lacked the capability to quantify effectively 3D features from coral reef habitats. Recent advancements in SfM technology have equipped marine scientists with the ability to create high-resolution and spatially accurate reconstructions of benthic habitats (Burns et al. 2015, Figueira et al. 2015, Leon et al. 2015, Burns et al. 2016, Ferrari et al. 2016, Couch et al. 2017, Fukunaga et al., 2019, Magel et al. 2019). Integrating the 3D spatial data derived from SfM technologies with conventional 2D monitoring metrics (e.g., live coral cover, coral diversity, coral size) will contribute to our understanding of the ecological role of various coral morphotypes. As scientists work towards identifying the specific metrics of 3D habitat structure that drive the abundance and diversity of reef organisms, it will be critical to know which specific coral species and morphologies are responsible for creating those habitat types.

Our study provides new insight into the important role coral assemblage structure plays in driving 3D reef habitat structural complexity. The long-term study plots at French Frigate Shoals exhibit statistically significant relationships among coral assemblage structure and 3D structural complexity of the benthic habitat. These results can help managers understand and predict how changes in coral assemblage structure, caused by environmental disturbances, may affect the structural complexity 
of coral reef habitats. As we determine the direct underpinnings linking 3D complexity to specific ecological processes, this information will become vital for determining how ecosystem function and services will be affected by changing climate conditions.

\section{ACKNOWLEDGEMENTS}

We thank the officers and crew of NOAA ship Hi'ialakai for logistic support and field assistance. Image and data processing were completed in the UHH Multiscale Environmental Graphical Analysis (MEGA) Lab. B. Craig was supported by NOAA Ernest F. Hollings Scholarship during this project. This work was funded by NOAA's Office of National Marine Sanctuaries, through the Papahānaumokuākea Marine National Monument, and by the National Science Foundation under the CREST-PRF Award \#1720706 and EPSCoR Program Award OIA \#1557349 to J. Burns. The scientific results and conclusions, as well as any views or opinions expressed herein, are those of the authors and do not necessarily reflect the views of NSF, NOAA or the Department of Commerce.

\section{REFERENCES}

Alvarez-Filip, L., Dulvy, N.K., Gill, J.A., Côté, I.M., Watkinson, A.R., 2009 Flattening of Caribbean coral reefs: region-wide declines in architectural complexity. Proc R Soc Lond B Biol 276:3019-3025

Alvarez-Filip, L., N.K. Dulvy, I.M. Cote, A.R. Watkinson, and J.A. Gill., 2011. Coral identify underpins architectural complexity on Caribbean reefs. Ecological Applications 21(6):2223-2231

Anderson, M.J., Robinson, J., 2003. Generalized discriminant analysis based on distances. Aust N Z J Stat 45: 3301-3318

Anderson, M.J., Willis, T.J., 2003. Canonical analysis of principal coordinates: a useful method of constrained ordination for ecology. Ecology 84: 511-525

Beijbom, O., Edmunds, P.J., Kline, D.I., Mitchell, B.G., Kriegman, D., 2012. Computer vision and pattern recognition (CVPR). In:2012 IEEE Conference on Rhode Island

Burns, J.H.R., Delparte, D., Gates, R.D. and Takabayashi, M., 2015. Integrating structure-from-motion photogrammetry with geospatial software as a novel technique for quantifying 3D ecological characteristics of coral reefs. PeerJ, 3, p.e1077

Burns et al. (2016) Assessing the impact of acute disturbances on the structure and composition of a coral community using innovative $3 \mathrm{D}$ reconstruction techniques. Methods in Oceanography 15/16: 49-59

Couch, C.S., Burns, J.H.R., Liu, G., Steward, K., Gutlay, T.N., Kenyon, J., et al., 2017. Mass coral bleaching due to unprecedented marine heatwave in Papahānaumokuākea Marine National Monument (Northwestern Hawaiian Islands). PLoS ONE12(9): e0185121

Costanza, R., R. d'Arge, R. de Groot, S. Farber, M. Grasso, B. Hannon, K. Limburg, S. Naeem, R.V. O’Neill, J. Paruelo, R.G. Raskin, P. Sutton, and M. van den Belt., 1997. The value of the world's ecosystem services and natural capital. Nature 387: 253260

Crowder, L.B., W.E. Cooper., 1982. Habitat structural complexity and the interaction between bluegills and their prey. Ecology 63:1802-1813
Darling, E.S., McClanahan, T.R., Côté, I.M., 2013. Life histories predict coral community disassembly under multiple stressors. Glob Chang Biol. Jun; 19(6):1930-40

Delparte, D.M., M. Belt, C. Nishioka, N. Turner, R. Richardson, and T. Ericksen., 2014. Monitoring tropical alpine lake levels in a culturally sensitive environment utilizing 3D technological approaches. Arctic, Antarctic, and Alpine Research 46(4):709718

Dustan, P., O. Doherty, S. Pardede., 2013. Digital reef rugosity estimates coral reef habitat complexity. PLoS ONE 8(2):e57386

Ferrari, R., McKinnon, D., He, H., Smith, R.N., Corke, P., González-Rivero, M., Mumby, P.J. and Upcroft, B., 2016. Quantifying multiscale habitat structural complexity: a costeffective framework for underwater 3D modelling. Remote Sensing, 8(2), p.113

Figueira, W., Ferrari, R., Weatherby, E., Porter, A., Hawes, S. and Byrne, M., 2015. Accuracy and precision of habitat structural complexity metrics derived from underwater photogrammetry. Remote Sensing, 7(12), pp.16883-16900

Fonstad, M.A., J.T. Dietrich, B.C. Courville, J.L. Jensen, and P.E. Carbonneau., 2013. Topographic structure from motion: a new development in photogrammetric measurement. Earth Surface Processes and Landforms DOI:10.1002/esp.3366

Fukunaga, A.F., Burns, J.H.R., Craig, B.K., Kosaki, R.K., 2019. Integrating Three-Dimensional Benthic Habitat Characterization Techniques into Ecological Monitoring of Coral Reefs. J. Mar. Sci. Eng. 7(2): 27

Gates, R.D., Ainsworth, T.D., 2011. The nature and taxonomic composition of coral symbiomes as drivers of performance limits in scleractinian corals. Journal of Experimental Marine Biology and Ecology 408:94-101

Goreau, T.F. 1959. The ecology of Jamaican coral reefs 1. Species composition and zonation. Ecology 40:67-90

Graham, N.A.J., Wilson, S.K., Jennings, S., Polunin, N.V.C., Bijoux, J.P., Robinson, J., 2006. Dynamic fragility of oceanic coral reef ecosystems. Proc Natl Acad Sci USA 103:8425-8429

Graham, N.A.J., and K.L. Nash., 2013. The importance of structural complexity in coral reef ecosystems. Coral Reefs $32: 315-326$

Guinan, J., C. Brown, M.F.J. Dolan, and A.J. Grehan., 2009. Ecological niche modeling of the distribution of cold-water coral habitat using underwater remote sensing data. Ecological Informatics 4:83-92

Harvell, C.D., Jordan-Dahlgren, E., Merkel, S., Rosenberg, E., Raymundo, L., et al., 2007. Coral disease, environmental drivers and the balance between coral and microbial associates. Oceanography 20: $58-81$

Hoegh-Guldberg, O., P.J. Mumby, A.J. Hooten, R.S. Steneck, P. Greenfield, E. Gomez, C.D. Harvell, P.F. Sale, A.J. Edwards, K. Caldeira, N. Knowlton, C.M. Eakin, R. Iglesias-Prieto, N. Muthiga, R.H. Bradbury, A. Dubi, and M.E. Hatziolos., 2007. Coral Reefs Under Rapid Climate Change and Ocean Acidification. Science 318:1737-1742 
House, J.E., Brambilla, V., Bidaut, L.M., Christie, A.P., Pizarro, O., Madin, J.S., Dornelas, M., 2018. Moving to 3D: relationships between coral planar area, surface area and volume. PeerJ 6:e4280

Hughes, T.P., Kerry, J.T., Baird, A.H., Connolly, S.R., Dietzel, A., Eakin, C.M., Heron, S.F., Hoey, A.S., Hoogenboom, M.O., Liu, G. and McWilliam, M.J., 2018. Global warming transforms coral reef assemblages. Nature, 556(7702), p.492

Huston, MA., 1979. A general hypothesis of species diversity. Am. Nat. 113:81-101

Javernick, L., J. Brasington, and B. Caruso., 2014. Modeling the topography of shallow braided rivers using Structure-fromMotion photogrammetry. Geomorphology 213:166-182

Jones, C.G., Lawton, J.H., Shachak, M., 1996. Organisms as ecosystem engineers In Ecosystem Management (eds Samson, F. B. \& Knopf, F. L.) 130-147 (Springer)

Knudby, A., and E. LeDrew., 2007. Measuring structural complexity on coral reefs. In: Pollock NW, Godfrey JM, eds. Diving for Science 2007. Proc of the American Academy of Underwater Sciences 26 $6^{\text {th }}$ Symposium pgs:181-188

Knowlton, N., 2001. The future of coral reefs. Proc Natl Acad Sci USA 98: 5419-5425

Kostylev, V.E., J. Erlandsson, M.Y. Ming, and G.A. Williams., 2005. The relative importance of habitat complexity and surface area in assessing biodiversity: Fractal application on rocky shores. Ecological Complexity 2:272-286

Leon, J.X., Roelfsema, C.M., Saunders, M.I. and Phinn, S.R., 2015. Measuring coral reef terrain roughness using 'Structurefrom-Motion'close-range photogrammetry. Geomorphology, 242, pp. $21-28$

Legendre, P., Anderson, J.M., 1999. Distance-based redundancy analysis: testing multispecies responses in multifactorial ecological experiments. Ecological Monograph 69: 1-24

Leujak, W., Ormond, R.F.G., 2007. Comparative accuracy and efficiency of six coral community survey methods. Journal of Experimental Marine Biology and Ecology. 351:168-187

Luckhurst, B.E., and K. Luckhurst., 1978. Analysis of the influence of substrate variables on coral reef fish communities. Marine Biology 49:317-323

McArdle, B.H., Anderson, M.J., 2001. Fitting multivariate models to community data: a comment on distance-based redundancy analysis. Ecology 82: 290-297

MacArthur, R. H., 1984. Geographical ecology, patterns in the distributions of species. Princeton University Press, Princeton, New Jersey, USA

Magel, J.M.T., Burns, J.H.R., Gates, R.D., Baum, J.K., 2019. Effects of bleaching-associated mass coral mortality on reef structural complexity across a gradient of local disturbance. Scientific Reports. 9(1) 2512

Moberg, F., Folke, C., 1999 Ecological goods and services of coral reef ecosystems. Ecological Economics 29:215-233

Nash, K.L., et al. 2014. Discontinuities, cross-scale patterns, and the organization of ecosystems. Ecology. 95:654-667
Noonan, S.H.C., Jones, G.P., Pratchett M.S., 2012. Coral size, health and structural complexity: effects on the ecology of a coral reef damselfish. Marine Ecology Progress Series. 456:127-137

Remondino, F., Spera, M.G., Nocerino, E., Menna, F., Nex, F., 2014. State of the art in high density image matching. In: The Photogrammetric Record 29, pp. 144-166. doi:10.1111/ phor. 12063

Pratchett, M., Trapon, M., Berumen, M., Chong-Seng, K., 2011. Recent disturbances augment community shifts in coral assemblages in Moorea, French Polynesia. Coral Reefs 30:183193

Richardson, L.E., Graham, N.A.J., Hoey, A.S., 2017. Cross-scale habitat structure driven by coral species composition on tropical reefs. Sci Rep 7: 7577

Risk, M.J., 1972. Fish diversity on a coral reef in the Virgin Islands. Atoll Research Bulletin 153

Snavely, N., S.N. Seitz, and R. Szeliski., 2008. Modeling the world from internet photo collections. International Journal of Computer Vision 80:189-210

Stachowicz, J.J., 2001. Mutualism, facilitation, and the structure of ecological communities. Bioscience. 51:235-246

Storlazzi, C.D., Dartnell, P., Hatcher, G.A., Gibbs, A.E., 2016. End of the chain? Rugosity and fine-scale bathymetry from existing underwater digital imagery using structure-from-motion (SfM) technology. Coral Reefs. 35:889-894

Todd, P.A., 2008. Morphological plasticity in scleractinian corals. Biol Rev Camb Philos Soc. Aug; 83(3):315-37

Walbridge, S.; Slocum, N.; Pobuda, M.; Wright, D.J. 2018. Unified geomorphological analysis workflows with Benthic Terrain Modeler. Geosciences 8; 94

Walker, B.K., L.K.B Jordan, and R.E. Spieler., 2009. Relationship of reef fish assemblages and topographic complexity on Southeastern Florida Coral Reef Habitats. Journal of Coastal Research 25(6):39-48

Westoby, M.J., J. Brasington, N.F. Glasser, M.J. Hambrey, and J.M. Reynolds., 2012. 'Structure-from-Motion' photogrammetry: A low-cost, effective tool for geoscience applications. Geomorphology 179:300-314

Woesik, R., Sakai, K., Ganase, A., Loya, Y., 2011. Revisiting the winners and losers a decade after coral bleaching. Marine Ecology Progress Series 434:67-76 